\title{
Modified Presurgical NAM: A Comparative Clinical Evaluation in Complete Unilateral Cleft Lip and Palate Management
}

Dr. Alka Rani ${ }^{1 *}$, Dr. Seema Thakur ${ }^{2}$, Dr. Devashish ${ }^{3}$, Dr. Vijay Kumar Diwana ${ }^{4}$, Dr. Tripti Chauhan ${ }^{5}$, Dr. Kapil Dev Sharma ${ }^{6}$

\author{
${ }^{1}$ Senior Resident, Department of Pedodontics and Preventive Dentistry, KGMU, Lucknow, U.P, India \\ ${ }^{2}$ Professor and Head, Department of Pedodontics and Preventive Dentistry, Himachal Pradesh Govt. Dental College and Hospital, Shimla, India \\ ${ }^{3}$ PGIMER, Chandigarh, India \\ ${ }^{4}$ Professor \& Head Department of Plastic Surgery, I.G.M.C, Ridge Sanjauli Rd, Lakkar Bazar, Shimla, Himachal Pradesh 171001, India \\ ${ }^{5}$ Assistant Professor Department of Community Medicine, I.G.M.C., Ridge Sanjauli Rd, Lakkar Bazar, Shimla, Himachal Pradesh 171001, India \\ ${ }^{6}$ Resident at Dr. RML Hospital, Lucknow, India
}

DOI: $10.36347 /$ sjds.2020.v07i09.005

| Received: 16.09.2020 | Accepted: 24.09.2020 | Published: 28.09.2020

*Corresponding author: Dr. Alka Rani

Abstract

Original Research Article

Background: Cleft lip and palate deformity presents one, of the most complex surgical challenges. Although surgical correction remains the cornerstone of treating this deformity, some inadequacies still remains. PresurgicalNasoalveolar molding (PNAM) is used as an adjunct to reduce and reshaping the alveolar and nasal defect. In the original Grayson's technique has some limitations such as frequent appointment and recall, and ulcerations so Figueroa modified PNAM technique (less researched) was selected for PNAM in the present study as it allows nasal and alveolar moulding at the same time thereby reducing the requirement of appointments for adjustments. Aim: To evaluate the effectiveness of Figueroa modified PNAM as a method of improving nasal symmetry and alveolar cleft in patients with UCLP (Unilateral Cleft Lip and Palate). Materials and Methods: Total number of Thirty $(\mathrm{n}=30)$ children of less than one year of age, with cleft lip and palate were selected for the study. These were equally divided into 2 groups, group I treated with PNAM appliance, using Figueroa modified PNAM technique \& followed by surgical lip repair and group II (control group) where primary cheilioplasty was carried out without PNAM. These patients were evaluated at various intervals and compared for various alveolar and nasal parameters, (nostril height, nostril width, columellar height, Bi-alar width and Intersegment distance. Data obtained from comparison of the groups were analyzed using-test. Results: A significant improvement of nasal symmetry and reduction of alveolar cleft gap on the cleft side in the PNAM group was observed in the PNAM group as compared to the control group. Conclusion: The Figueroa modified PNAM technique is efficient, cost effective and less tedious, that can reduce the number of future secondary surgeries. Studies with wider patient base, randomization and longer follow-ups are needed for definitive results.

Keywords: Cleft, Pre Surgical Orthopedics, Nasoalveolar, Molding.

Copyright @ 2020: This is an open-access article distributed under the terms of the Creative Commons Attribution license which permits unrestricted use, distribution, and reproduction in any medium for non-commercial use (NonCommercial, or CC-BY-NC) provided the original author and source are credited.

\section{INTRODUCTION}

Cleft of the lip, and palate (CLAP) are the most common congenital deformity of the head and neck. The pre-surgical nasoalveolar moulding (NAM) as a method of pre-surgical orthopaedics is gaining popularity in the cleft treatment protocols [1]. Previously used methods and techniques for CLAP management were limited to the correction of the alveolar cleft gap only, despite the fact that the cleft nasal deformity remains the major aesthetic challenge [2]. Nasal deformity in unilateral cleft lip and palate patients increases with time leading to abnormal growth pattern which causes a great deal of personal, social, and psychological morbidity [2]. Before the introduction of the concept of PNAM, repair of a wide cleft involved several surgeries from birth to adolescence, setting the child at risk for emotional and social adjustment stigmas Alar cartilage, which is elastic like auricular cartilage, is correctable in the early neonatal period [3]. Considering this Grayson and Cutting combined the concept of pre-surgical orthopaedics in the cleft lip nasal deformity, and developed the concepts of Pre-surgical Nasoalveolar Moulding (PNAM), which combined a nasal moulding stent with a passive, pre-surgical moulding appliance in treating cleft lip and palate infants [7]. 
In the original Grayson's technique adjustments in the appliance are made weekly and nasal stents are added when the alveolar gap is reduced to 5 $\mathrm{mm}$ [7]. It makes this procedure more tedious, bothersome for the parents and patients in term of multiple adjustments and visits [9-11].

In Figueroa modified PNAM technique, nasal and alveolar moulding are done at the same time to reduce the number of adjustments till cheiloplasty [10]. This procedure is less commonly researched, with few investigations on its efficacy [11]. Therefore the purpose of this study was to evaluate the effect of Figueroa modified PNAM technique on nasal symmetry and alveolar cleft deformity, in the patients with complete unilateral CLAP.

\section{MATERIAL AND METHOD}

This Prospective study was conducted at Himachal Pradesh Govt. Dental College and Hospital after receiving the institutional ethical approval. The study included thirty $(n=30)$ non-syndromic infants with unilateral cleft lip and palate (UCLP) after obtaining written informed consent from their parents. The subjects were divided into two groups, Group I, the study group $(\mathrm{N}=15)$, with unilateral cleft lip and palate (0-6 months), underwent the PNAM (Modified Figeuroa technique), fig. Group II, control group $(\mathrm{N}=15)$ with unilateral cleft lip and palate, treated surgically without any pre-surgical intervention.

In group I, the PNAM was started as early in 10 to 15 - day- old infant, and the average duration of the therapy was 6 months. On completion of PNAM, the study group was subjected to conventional surgical repair of CLAP. The surgical repair in both the groups was carried out by the same plastic surgeon. All the nasal parameters were recorded over the face with the help of Vernier calliper and alveolar parameter (intersegmental distance) was recorded over study cast models. Pre-treatment records in both the groups, post PNAM records (Post-Surgical in Group II) were taken by a single Pedodontist.

The PNAM appliance fabrication and steps involved the impression making using elastomeric impression material, (Addition silicone- 3M) in putty consistency. A dental stone cast was obtained and wax $^{-}$up of the cast was done according to the contour and topography of the intact arch as per the Figueroa's PNAM technique, before the fabrication of the moulding plate. The moulding plate was fabricated using self- cure clear acrylic on the waxed up cast. A nasal stent was added at the same time of fabrication of moulding plate (Fig 1-6). The complete appliance was delivered and the patients were recalled initially after 24 $\mathrm{hr}$ to check for problem due to appliance and later every 3-4 weeks for adjustments till primary cheiloplasty. Adjustments in the appliance was done using selective grinding and addition of soft denture liner.

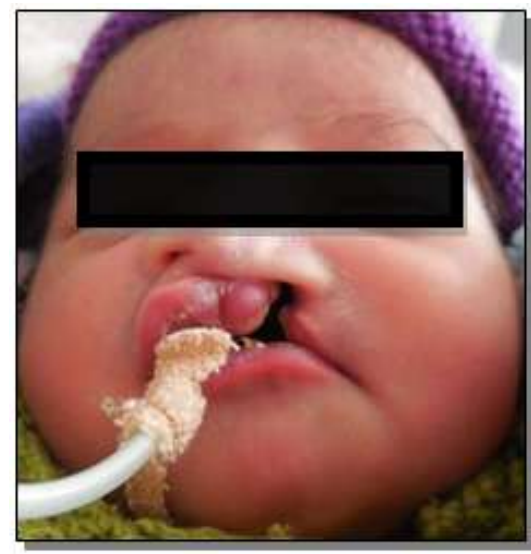

Fig-1: Preoperative Frontal View

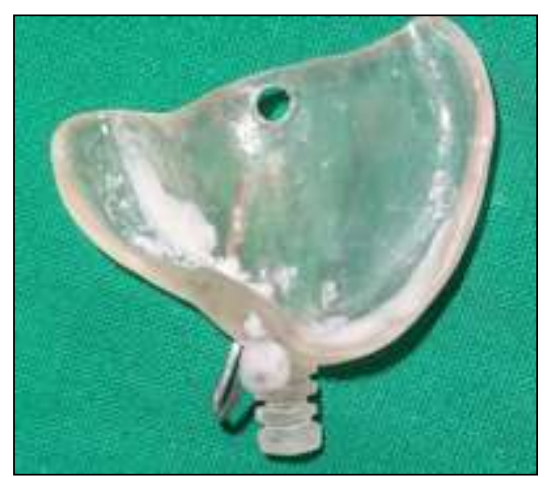

Fig-2: NAM Appliance

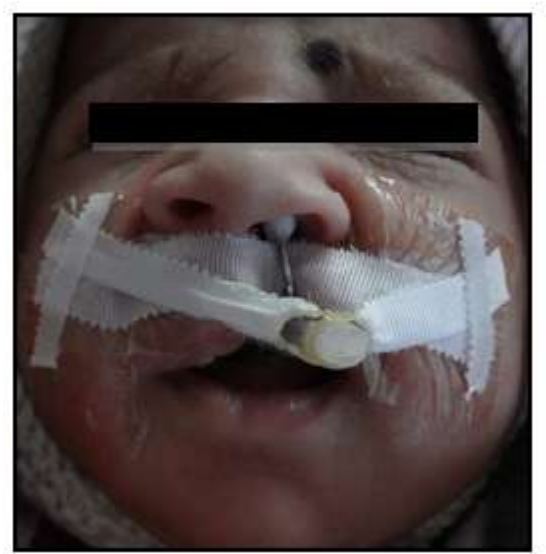

Fig 3: Lip Taping and Appliance Insertion

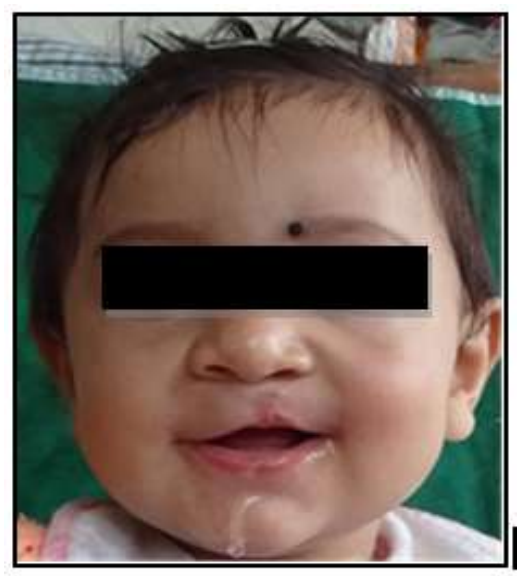

Fig-4: Post-Operative Frontal View 


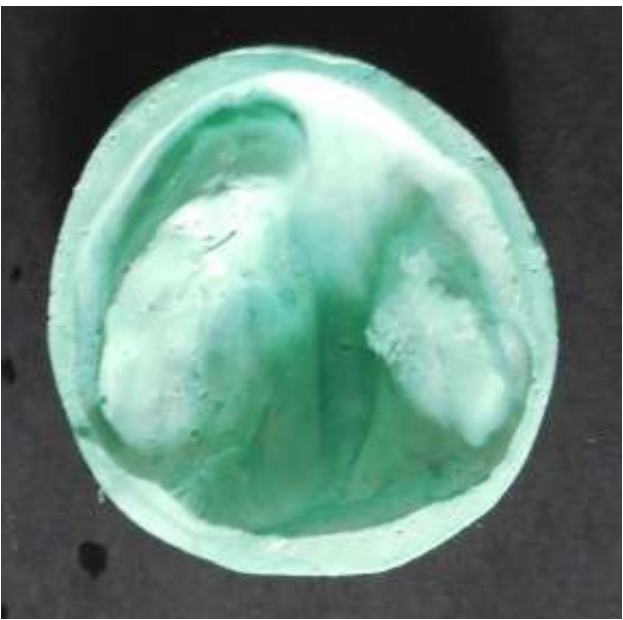

Fig-5: Pre-Operative Cast Model

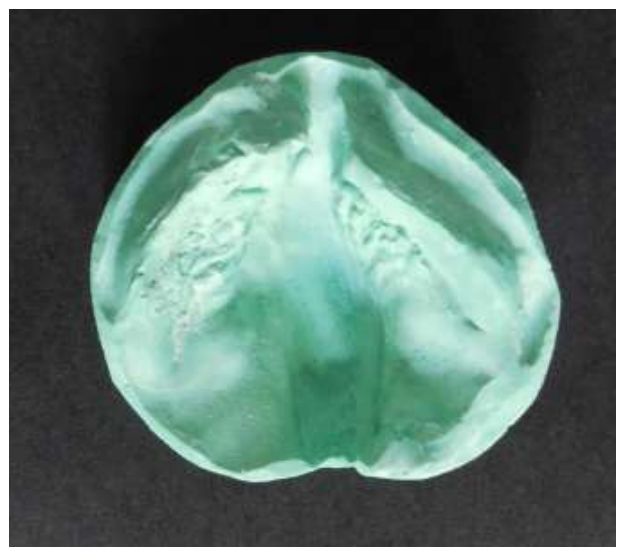

Fig-6: Post-Operative Cast Model

\section{Assessment of the Study Models and Facial Photographs \\ Photographic Analysis}

Nasal parameters were measured over the patient's face (using vernier calliper with $.01 \mathrm{~mm}$ precision) and photographs respectively. Standard photographic views, pictures and their measurements were done using the aid of the computer. Intersegmental distance was measured over the dental stone models (Fig $5 \& 6$ ). Nasal symmetry was quantified by the following linear anthropometric measurements such as nostril height, nostril width, bi-alar width, and columellar height. Primary lip repair was done on completion of PNAM depending on the improvement of nasal and alveolar parameters. All measurements in both the groups were recorded twice, once just before any intervention and then, one week post completion of PNAM in group I and the primary lip repair in the control group.

All the data obtained from the two groups was subjected to statistical analysis. All statistical analyses were performed using SPSS version 26.0 (SPSS Inc. South Wacker Drive, Chicago, United States). Comparison was done using a two- tailed sample $\mathrm{t}^{-}$test or a $\mathrm{Chi}^{-}$square test when indicated. For significance $\mathrm{p}$ value of $<0.05$ was considered to be significant.

\section{RESULTS}

Among all the subjects $71.9 \%$ were boys and $29.1 \%$ were girls.

\section{Post NAM Outcomes in Group 1 Subjects}

On comparison of pre and post PNAM Outcomes (nasal and alveolar parameters) this modified PNAM had been proved an effective pre-surgical intervention for the improvement of nasal symmetry and reduction of alveolar gap in complete unilateral cleft lip and palate patients (Table-1).

Table-1: Pre and Post-NAM Outcome Comparison in Group I

\begin{tabular}{|c|c|c|c|c|c|c|}
\hline \multirow[t]{2}{*}{ Parameters } & & \multicolumn{2}{|c|}{ Pre treatment } & \multicolumn{2}{|c|}{ Post treatment } & \multirow[t]{2}{*}{ p value } \\
\hline & & Mean & SD & Mean & SD & \\
\hline \multirow[t]{2}{*}{$\mathrm{NH}$} & $\mathrm{C}$ & 2.00 & 0.63 & 4.58 & 0.49 & $<0.001$ \\
\hline & $\mathrm{NC}$ & 5.33 & 0.51 & 5.83 & 0.75 & 2.09 \\
\hline \multirow[t]{2}{*}{ NW } & $\mathrm{C}$ & 15.16 & 2.78 & 9.33 & 2.87 & $<0.001$ \\
\hline & $\mathrm{NC}$ & 7.41 & 2.76 & 7.75 & 3.25 & 1.85 \\
\hline $\mathrm{CH}$ & & 1.33 & 0.51 & 4.5 & 0.54 & $<0.001$ \\
\hline BAW & & 25.5 & 1.04 & 20.83 & 0.75 & $<0.05$ \\
\hline ISD & & 9.16 & 2.92 & 2.33 & 1.50 & $<0.001$ \\
\hline
\end{tabular}

Measurements in $\mathrm{mm}, \mathrm{C}=$ cleft side, $\mathrm{NC}=$ non-cleft side, $\mathrm{NH}=$ nostril height, $\mathrm{NW}=$ nostril width, $\mathrm{CH}=$ columellar height, $\mathrm{BAW}=\mathrm{bi}$-alar width, ISD=Intersegment distance. ${ }^{*} \mathrm{p}<0.05$ significant

In group I, on comparison of pre-treatment vs post PNAM results on the cleft side, increase in nostril height was observed $(2 \pm 0.63$ vs $4.58 \pm 0.49)$ ( $\mathrm{p}<.001)$. There was no significant change on the non cleft side. Nostril width was found to be reduced on cleft side $(15.16 \pm 2.78$ vs $9.33 \pm 2.87 ; \mathrm{p}<0.001)$. As a positive outcome of PNAM in group I subjects, increase in the columellar height $(1.33 \pm 0.51$ vs $4.5 \pm 0.54$; $<.001)$ was observed on the cleft side. Decrease in the bi-alar width $(25.5 \pm 1.04$ vs $20.83 \pm 0.75) ; \mathrm{p}<0.05$ was also recorded. Intersegment distance was observed to decrease post PNAM $(9.16 \pm 2.92$ vs $2.33 \pm 1.50$; $\mathrm{p}<0.001)$. Overall results showed a significant improvement in nasal symmetry and reduction of intersegmental cleft distance. 
Table-2: Pre and Post treatment (within one week of Post Surgery) comparison of nasal and intraoral parameters in group II subjects

\begin{tabular}{|l|l|l|l|l|l|l|}
\hline Parameters & Side of the face & \multicolumn{2}{l|}{ Pre-treatment } & \multicolumn{2}{l|}{ Post treatment } & p value \\
\hline & & Mean & SD & Mean & SD & \\
\hline \multirow{2}{*}{ NH } & C & 2.01 & 0.62 & 3.05 & 0.58 & $<0.05$ \\
\cline { 2 - 8 } & NC & 4.32 & 0.51 & 4.83 & 0.75 & 0.18 \\
\hline \multirow{2}{*}{ NW } & C & 15.18 & 2.79 & 11.91 & 2.61 & $<0.05$ \\
\cline { 2 - 7 } & NC & 6.91 & 2.50 & 7.08 & 3.09 & $=0.85$ \\
\hline CH & 1.28 & 0.20 & 2.86 & 0.21 & $<0.001$ \\
\hline BAW & 25.3 & 1.03 & 23.51 & 0.89 & 2.12 \\
\hline ISD & *p<0.05 significant & 9.14 & 2.90 & 8.09 & 2.78 & 0.31 \\
\hline
\end{tabular}

In group II, control group, on comparison of pre-treatment vs post surgical results (1 week of surgery) on the cleft side showed increase in nostril height, $(2.01 \pm 0.62$ vs $3.05 \pm 0.58 ; \mathrm{p}<.05)$. Nostril width was found to be reduced post surgery on cleft side $(15.18 \pm 2.79$ vs $11.91 \pm 2.61 ; \mathrm{p}<0.05)$. Increase in the columellar height $(1.28 \pm 0.20$ vs $2.86 \pm 0.21)$ (p $<0.001)$ was observed on the cleft side. Decrease in the bi-alar width $(25.3 \pm 1.03$ vs $23.51 \pm 0.89 ; \mathrm{p}=2.12)$ was observed. Intersegment distance was also observed to decrease $(9.14 \pm 2.90$ vs $8.09 \pm 2.78 ; \mathrm{p}=0.31)$. Overall results showed a significant improvement in nasal symmetry and reduction of intersegmental cleft distance but the difference in improvement was less as compared to Group I i.e. treatment with PNAM group (Table-3).

\section{Post Treatment Outcome (Change) Comparison between the Groups}

Post treatment outcomes for nasal and alveolar parameters was compared on the basis of change in various measurements pre and post operatively (Table$3)$.

Table-3: Post Treatment Change In Various Parameters between the Groups on the Cleft Side

\begin{tabular}{|l|l|l|l|l|l|}
\hline S.no & Parameter measured & \multicolumn{2}{l|}{ Group- I } & \multicolumn{2}{l|}{ Group- II } \\
\hline 1 & Nostril Height & 2.58 & 0.15 & 1.04 & 0.12 \\
\hline 2 & Nostril Width & -5.83 & 0.98 & -3.27 & 2.61 \\
\hline 3 & Columellar Height & 3.17 & 0.25 & 1.58 & 0.19 \\
\hline 4 & Bi-alar width & -4.67 & -1.13 & -1.79 & 0.21 \\
\hline 5 & Inter-segmental distance & -6.83 & -1.72 & -1.05 & 0.49 \\
\hline
\end{tabular}

\section{Nostril Height}

The nostril height on cleft side increased in both the groups post intervention but the change was more significant in the PNAM group as compared to surgery only group $(2.58 \pm 0.15$ vs $1.04 \pm 0.12)$ (Table$3)$.

\section{Nostril Width}

Nostril width on cleft side decreased in both the groups but the difference was more in PNAM group as compared to the control group $(-5.83 \pm 0.98$ vs -3.27 $\pm 2.61 \mathrm{~mm}$ ) (Table-3).

\section{Columellar Height and Bi-Alar Width}

Post intervention, in both the groups columellar height on the cleft side was observed to increase. This difference was remarkable in Group I as compared to Group II $(3.17 \pm 0.25$ vs $1.58 \pm 0.19)$ (Table-3).

The post procedural reduction of bialar width was more in group I vs group II where minimal reduction was observed $(-4.67 \pm 1.13$ vs $-1.79 \pm 0.21)$ (Table-3).

\section{Inter-Segmental Distance (ISD)}

Decrease in the Intersegmental distance is considered as a positive outcome of treatment. It was observed to decrease in both the groups but by a much higher margin in goup I vs group II. (-6.83 \pm 1.72 vs $1.05 \pm 0.49$ ) (Table-3).

\section{DISCUSSION}

If cleft patients are treated without any presurgical interventions, then nasal deformity increases with the time, and remain the greatest aesthetic challenge [2]. Any form of the nonsurgical treatment to reduce the nasal deformity early in the life is therefore highly desirable.

First attempt at the pre-surgical nasal correction was made by Matsuo et al. who highlighted the role of preoperative moulding in changing the cartilage memory of deformed nasal cartilage [3]. As these cartilages have higher amount of hyaluronic acid, which gradually diminishes after few months of birth it is desirable to start the PNAM procedures as early as possible [2]. 
The PNAM technique offers both the advantages of not only improving the soft tissue but also the bony segments approximation thereby improving the overall function and aesthetics before the primary lip repair $[4,5]$.

The PNAM was begun at New York university medical centre in 1992-93 by Dr. Berry H. Grayson, an orthodontist [7]. The average age to start PNAM therapy is the $26^{\text {th }}$ day after birth and the average treatment period of PNAM is 110 days [6].

Literature on Grayson's nasoalveolar moulding technique, as an effective method to treat cleft nose deformity is abundant [7, 8]. It has its limitations such as facial irritation, mucosal ulceration and the requirement of frequent appointments for appliance adjustments [9-11]. The parents' socioeconomic status, climatic condition and topography of Himachal Pradesh were limitations for the parents for weekly appointments for follow up and adjustments as required in the Grayson's technique.

So, Figueroa modified PNAM technique was chosen in the present study as it allowed performance of nasal and alveolar moulding at the same time minimizing frequent follow-up visits from weekly to once every 3-4 weeks for moulding [10]. It lead to a significant improvement in the nasal shape and symmetry both in the vertical (nostril height and columellar length) as well as horizontal dimensions (nostril width and bi-alar width) before primary cheiloplasty (Table $1 \& 2$ ). The results are in consonance with the studies done by Suri et al., Clarke et al., Panga et al., and Thakur et al., [1, 12, 13, 22]. Authors such as Williams et al., Mishra et al., and LI $\mathrm{SN}$ et al., did not report any significant difference in nostril width and alar perimeter [14-16].

The alveolar cleft width reduction (intersegmental distance) were accomplished using adhesive tape tractions applied across the cleft lip as proposed by Grayson et al., [7]. In the present study, the intersegmental distance (maxillary cast measurement) was reduced by $6.83 \mathrm{~mm}$ after 4 months of PNAM procedure in the group I as compared to only 1.05 in the surgery only group (Table-3). Most of the study have reported reduction in the intersegmental distance have used Grayson's method of PNAM. Ezzat et al., Baek et al., Pai et al., also reported a similar reduction of 5.8 $\mathrm{mm}$ after 3-4 months of PNAM treatment [6, 17, 18]. Few studies Bongaarts et al., and Isogawa have reported no significant effects of PNAM on the width of alveolar gap [19, 20]. Literature is scarce on the assessment of alveolar changes using Figueroa's PNAM technique. A significant reduction in the alveolar gap was reported by Singh A et al., using Figueroa's PNAM technique [21].
The reduced alveolar cleft gap (intersegmental distance) after NAM may lead to avoidance of surgery in future like secondary alveolar bone grafting and rhinoplasties. This technique had proven to be beneficial for the surgeon and patient both alike.

In present study nasal symmetry was significantly improved, including positive changes in all the nasal and alveolar parameters. Limitations of present study can be considered in terms of small sample size, smaller follow-up period and treating control group subjects without PNAM.

\section{CONCLUSION}

In terms of reduction of appliance adjustments, parents visits, improvement of nasal anatomy and reduction of alveolar cleft gap, Figueroa modified technique has been an efficient and effective technique, to treat complete unilateral cleft lip and palate patients. PNAM therapy is a useful adjunctive treatment and it should be considered as a routine procedure in treatment protocol for cleft infants before primary cheilioplasty. Emphasis is laid on the need for large sample size studies with randomization to confirm the findings of this study.

\section{Financial support: Nil.}

\section{REFRENCES}

1. Suri S, Disthaporn S, Atenafu EG, Fisher DM. Presurgical presentation of columellar features, nostril anatomy, and alveolar alignment in bilateral cleft lip and palate after infant orthopedics with and without nasoalveolar molding. The Cleft palate-craniofacial journal. 2012 May;49(3):31424.

2. Bennun RD, Perandones C, Sepliarsky VA, Chantiri SN, Aguirre MI, Dogliotti PL. Nonsurgical correction of nasal deformity in unilateral complete cleft lip: a 6-year follow-up. Plastic and reconstructive surgery. 1999 Sep;104(3):616-30.

3. Matsuo K, Hirose T. Preoperative non-surgical over-correction of cleft lip nasal deformity. British journal of plastic surgery. 1991 Jan 1;44(1):5-11.

4. Patil PG, Patil SP, Sarin S. Nasoalveolar molding and long- term postsurgical esthetics for unilateral cleft lip/palate: 5- year follow- up. Journal of Prosthodontics: Implant, Esthetic and Reconstructive Dentistry. 2011 Oct;20(7):577-82.

5. Ross RB, MacNamera MC. Effect of presurgical infant orthopedics on facial esthetics in complete bilateral cleft lip and palate. The Cleft PalateCraniofacial Journal. 1994 Jan;31(1):68-73.

6. Ezzat CF, Chavarria C, Teichgraeber JF, Chen JW, Stratmann RG, Gateno J, Xia JJ. Presurgical nasoalveolar molding therapy for the treatment of unilateral cleft lip and palate: a preliminary study. The Cleft palate-craniofacial journal. 2007 Jan;44(1):8-12. 
7. Grayson BH, Santiago PE, Brecht LE, Cutting CB. Presurgical nasoalveolar molding in infants with cleft lip and palate. The cleft palate-Craniofacial journal. 1999 Nov;36(6):486-98.

8. Maull DJ, Grayson BH, Cutting CB, Brecht LL, Bookstein FL, Khorrambadi D, Webb JA, Hurwitz DJ. Long-term effects of nasoalveolar molding on three-dimensional nasal shape in unilateral clefts. The Cleft palate-craniofacial journal. 1999 Sep;36(5):391-7.

9. Levy-Bercowski D, Abreu A, DeLeon E, Looney S, Stockstill J, Weiler M, Santiago PE. Complications and solutions in presurgical nasoalveolar molding therapy. The Cleft palatecraniofacial journal. 2009 Sep;46(5):521-8.

10. Koya S, Shetty S, Husain A, Khader M. Presurgical nasoalveolar molding therapy using Figueroa's NAM technique in unilateral cleft lip and palate patients: a preliminary study. Journal of Clinical Pediatric Dentistry. 2016 Jun;40(5):410-6.

11. Liao YF, Wang YC, Chen IJ, Pai CJ, Ko WC, Wang YC. Comparative outcomes of two nasoalveolar molding techniques for bilateral cleft nose deformity. Plastic and reconstructive surgery. 2014 Jan 1;133(1):103-10.

12. Clark SL, Teichgraeber JF, Fleshman RG, Shaw JD, Chavarria C, Kau CH, Gateno J, Xia JJ. Longterm treatment outcome of presurgical nasoalveolar molding in patients with unilateral cleft lip and palate. The Journal of craniofacial surgery. 2011 Jan;22(1):333.

13. Punga R, Sharma SM. Presurgical orthopaedic nasoalveolar molding in cleft lip and palate infants: a comparative evaluation of cases done with and without nasal stents. Journal of maxillofacial and oral surgery. 2013 Sep 1;12(3):273-88.

14. Williams ME,Evans CA,Reisberg JD, BeGole AE. Inter J Dent Volume 2012.

15. Mishra B, Singh AK, Zaidi J, Singh GK, Agrawal R, Kumar V. Presurgical nasoalveolar molding for correction of cleft lip nasal deformity: experience from northern India. Eplasty. 2010;10.
16. Si-nian LI, Tong-tong YA, Hong-liang QI, Yu-jing MI, Xiao-mei GO. The changes of palate cleft gap of complete unilateral cleft lip and palate infants before and after presurgical orthodontic and cheiloplasty. West China Journal of Stomatology. 2011 Jun 1;29(3).

17. Baek SH, Son WS. Difference in alveolar molding effect and growth in the cleft segments: 3dimensional analysis of unilateral cleft lip and palate patients. Oral Surgery, Oral Medicine, Oral Pathology, Oral Radiology, and Endodontology. 2006 Aug 1;102(2):160-8.

18. Pai BC, Ko EW, Huang CS, Liou EJ. Symmetry of the nose after presurgical nasoalveolar molding in infants with unilateral cleft lip and palate: a preliminary study. The Cleft palate-craniofacial journal. 2005 Nov;42(6):658-63.

19. Bongaarts CA, van't Hof MA, Prahl-Andersen B, Dirks IV, Kuijpers-Jagtman AM. Infant orthopedics has no effect on maxillary arch dimensions in the deciduous dentition of children with complete unilateral cleft lip and palate (Dutchcleft). The Cleft palate-craniofacial journal. 2006 Nov;43(6):665-72.

20. Isogawa $\mathrm{N}$, Ochiai $\mathrm{S}$, Mito $\mathrm{T}$, Kindaichi $\mathrm{J}$, Ishibashi N, Takagi Y, Ishikawa M. Threedimensional comparison in palatal forms between modified presurgical nasoalveolar molding plate and Hotz's plate applied to the infants with unilateral cleft lip and palate. Singapore dental journal. 2010 Jun 1;31(1):36-42.

21. Singh A, Thakur S, Singhal P, Diwana VK, Rani A. A comparative evaluation of efficacy and efficiency of grayson's presurgical nasoalveolar molding technique in patients with complete unilateral cleft lip and palate with those treated with figueroa's modified technique. Contemporary clinical dentistry. 2018 Jun;9(Suppl 1):S28.

22. Thakur S, Singh A, Thakur NS, Diwana VK. Achievement in nasal symmetry after cheiloplasty in unilateral cleft lip and palate infants treated with presurgical nasoalveolar molding. Contemporary clinical dentistry. $2018 \mathrm{Jul}$;9(3):357. 